\title{
TREE GROWTH AFTER TRENCHING AND COMPENSATORY CROWN PRUNING
}

\author{
by Gary W. Watson
}

\begin{abstract}
The roots of pin oak (Quercus palustris) trees were severed by trenching on 1,2 , or 3 sides the tree. The distance between the trunk and the trenches was approximately equal to the trunk circumference. Half of the trees also received compensatory crown pruning. All trees survived and significant dieback was noted only on trees that were trenched on 3 sides. Generally, the more extensive the trenching, the greater the growth reduction and dieback, and the longer the reduction persisted. Compensatory pruning increased twig growth for all trenching treatments, but seems to be most beneficial in reducing dieback after severe root loss from trenching. Under certain circumstances and in the absence of other construction impacts, vigorous trees may be able to tolerate and recover from trenching in the root zone.
\end{abstract}

Established trees on construction sites are often subject to mechanical damage and site changes that could eventually result in their decline and death. Damage to the root system is more difficult to evaluate even when easily observed as an open trench or an obvious grade change. In other situations, root damage may go completely unobserved if the site is not evaluated until after construction and final landscaping is completed, obscuring the cause of tree decline. Compacted soil may be just as damaging to root systems as direct mechanical damage (Ziza et al. 1980). Even if the tree root system is carefully protected during construction, other changes on the site, such as drainage, can alter the root environment within the protected zone. It can be difficult for arborists to evaluate separate and combined effects of the many types of treedamaging activities that may occur on a construction site and to predict their effect on the tree and its root system.

There is little published research to help specify how much of the root system must be protected for a reasonable chance of long-term survival.
Industry practices use above-ground tree features to specify dimensions of root protection zones. Branch spread (dripline) is most commonly used (Olson and Wray 1979; Schoeneweiss 1982; Fazio 1992; Miller et al. 1993 ). Trunk diameter (Morel 1984) and tree height (Miller et al. 1993) are also sometimes used to determine the size of the root protection zone. While these guidelines may be helpful, they have not been tested in controlled studies.

One purpose of this experiment was to study the long-term effects of root loss resulting from trenching in the absence of soil compaction, grade changes, and other factors. Specifications for augering near trees (Morel 1984) called for trenches to be no closer to the trunk than 8 to 12 $\mathrm{cm}$ for each $\mathrm{cm}$ of trunk diameter (8 to $12 \mathrm{in}$. for each inch) measured at breast height [dbh, 1.4 $\mathrm{m}(4.5 \mathrm{ft})$ above ground level]. When the specifications were followed, no growth reduction occurred (Miller and Neely 1993). When trenches were much closer to the trunk, growth was reduced. No trees died from the trenching. Young trees may be stressed by root loss but may be able to survive.

The practice of pruning to compensate for root loss has been used for years, but its value is often questioned. Pruning is intended to relieve stress by rebalancing the size of the crown with the reduced root system. But nearly half of the root system can be lost from a single trench near the base of the trunk. The crown cannot be pruned as extensively and still retain the natural form of the tree. Removing a significant number of branches is sometimes thought to eliminate vital carbohydrate production and reserves (Shigo 1993). The 2nd purpose of this experiment was to study the value of compensatory crown pruning after root loss from trenching. 


\section{Materials and Methods}

The trees used in the study were pin oaks (Quercus palustris), $29 \mathrm{~cm}$ (11.4 in.) average dbh, at The Morton Arboretum in Lisle, Illinois. The trees were planted in groups of 3 , spaced approximately $2 \mathrm{~m}(6 \mathrm{ft})$ between trees in a straight line. Groups were planted on $15 \mathrm{~m}$ ( $50 \mathrm{ft}$ ) centers. Five groups were incomplete (only 2 trees). A 3 rd tree from an adjacent incomplete group was used in these cases. All trees were in good health at the start of the experiment. Trenching and crown pruning treatments were assigned to the tree groups randomly.

Trenches were dug on May 29 and 30, 1991. The trenching was timed to subject the trees to sudden root loss when the leaves were nearly fully expanded, but not yet hardened-off. At this time, stress resulting from root loss was expected to be most severe.

Trees were trenched on 1, 2, or 3 sides (designated as treatments $1 T, 2 T$, and $3 T$, respectively) with a $1 \mathrm{~m}(3 \mathrm{ft})$ maximum depth trenching machine. Trenches were $15 \mathrm{~cm}$ (6 in.) wide, extending a distance of $30 \mathrm{~cm}(1 \mathrm{ft}$ ) from the trunk for each $2.5 \mathrm{~cm}(1 \mathrm{in}$.) dbh. Each tree in each group of 3 received a different trenching treatment (Figure 1). The distance between the trench and the base of the trunk was approximately equal to the trunk circumference with slight variations caused by machine access and tree spacing. Trenches were refilled with the same soil (all horizons mixed) and allowed to settle naturally. No other traffic or changes were permitted on the site.

No trenches were installed near the control (treatment C) groups of trees. Five groups were used as controls ( 15 trees), so that there would be 5 replicates of each relative position in the control groups (west end, center, and east end) in the event that position within the group affected growth.

Compensatory crown pruning was completed on the same days as the trenching (treatments 1TP, 2TP, and 3TP with 1, 2, or 3 trenches, respectively). A commercial tree care firm, Hendricksen, the Care of Trees, pruned the trees as they would do on an actual construction site. Trees were thinned moderately and lateral branches tipped

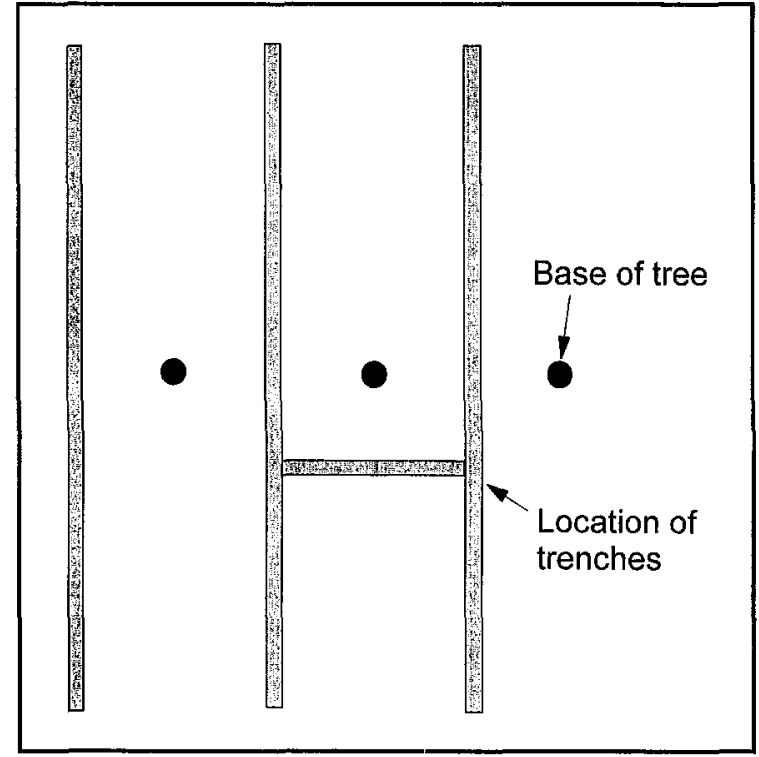

Figure 1. Typical trench configuration. Trench locations resulted in roots being cut on 1, 2, or 3 sides of the tree.

back 1 to $2 \mathrm{~m}$ ( 3 to $6 \mathrm{ft}$ ) to a strong lateral branch. The natural shape of the tree was not altered. It was visually estimated that $30 \%$ of the leaf area was removed. Only deadwood was removed from unpruned and control trees.

No supplemental watering was provided during the experiment. Normal precipitation averages from 7.5 to $10 \mathrm{~cm}$ ( 3 to 4 in.) per month during the growing season. But periods of several weeks without substantial rainfall are not uncommon. The first summer (June through August) was unusually dry. Only $35 \%$ of the normal rainfall was received. Nearly all of it came in amounts of 1 $\mathrm{cm}(0.4 \mathrm{in}$.) or less, which only moistens the surface soil briefly, and is little benefit to the tree.

Growth measurements were taken annually in September. Diameter (dbh) was measured at a mark painted on the trunk. Annual increases are expressed in Figure 2 as the difference between the treatment mean and control mean for each year. Twig growth was measured by averaging measurements from 4 branches on each tree, one from each side.

Dieback was estimated on a scale from 0 to 3. No dieback was rated 0 . Minor dieback of small lateral branches not affecting the form of the tree 


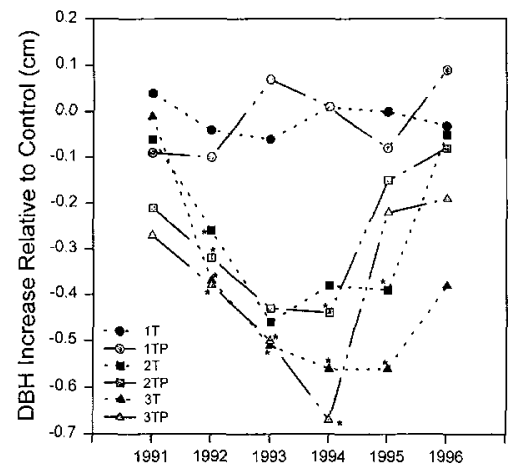

Figure 2. Annual dbh increase of pin oaks relative to control after root injury from trenching. An asterisk $\left(^{*}\right)$ denotes a significant difference from control at $\boldsymbol{P} \leq \mathbf{0 . 0 5}$ using Dunnett's test. Treatment key: $1 \mathrm{~T}, 2 \mathrm{~T}$, or $3 \mathrm{~T}$ indicates number of trenches, $P$ indicates crown pruning also.

was rated 1. Dieback of lateral branches to the extent that the shape of the tree was slightly disfigured was rated 2 . Extensive dieback of the laterals or central leader substantially reducing the amenity value of the tree was rated 3 .

Stored starch was estimated using iodine stain (Wargo 1975) on cross-sections of the 3 most recent annual rings of increment cores taken from the root flare just above the ground line.

One-way ANOVA was used to compare growth of treatments and control $(P \leq 0.05$ unless otherwise noted) using SigmaStat 2.0. Dunnett's test was used to separate means from control. The Student-Neuman-Keuls test was used for pairwise comparisons of treatments.

\section{Results and Discussion}

When growth and dieback data from the 3 separate control tree positions (west end, center, and east end) were compared, there were no significant differences resulting from position within the group. Data from all 15 control trees were combined.

Effect of trenching on growth and survival. Generally, the more severe the trenching treatment, the greater the growth reduction and the longer the reduction persisted. The most severe trenching treatment resulted in significant reductions in total $\mathrm{dbh}$ and twig growth compared to the controls (Figure 3). All trees survived.
Diameter growth. Diameter growth was reduced by trenching. When examining annual diameter increases of root loss treatments relative to controls (Figure 2), a single trench (1T) did not significantly reduce trunk diameter (dbh) increase in any year. Three trenches (3T) reduced growth significantly in every year except the 1st (trenches were installed after growth was mostly completed) and 6th. Two trenches (2T) resulted in a growth reduction pattern similar to the 3-trench treatments, but not quite as severe, and statistical separation from control was inconsistent.

Although growth reduction in the $3 \mathrm{~T}$ treatment was not significant in the 6th year, growth of trees was only $50 \%$ of the controls. Measurement difficulties may have been a factor. Difficulty in measuring the small annual growth increments of these stressed trees contributed to high variability because of the difficulty in placing the tape measure in the same exact position all the way around the trunk each time. With such a large growth reduction persisting, it may be inappropriate to conclude that these trees had recovered after the 6th year, but the trend of increasing growth indicates that total recovery may take only a year or 2 more.

Lack of significant growth reductions in 1993 and 1994 for $2 \mathrm{~T}$ treatment must also be inter-

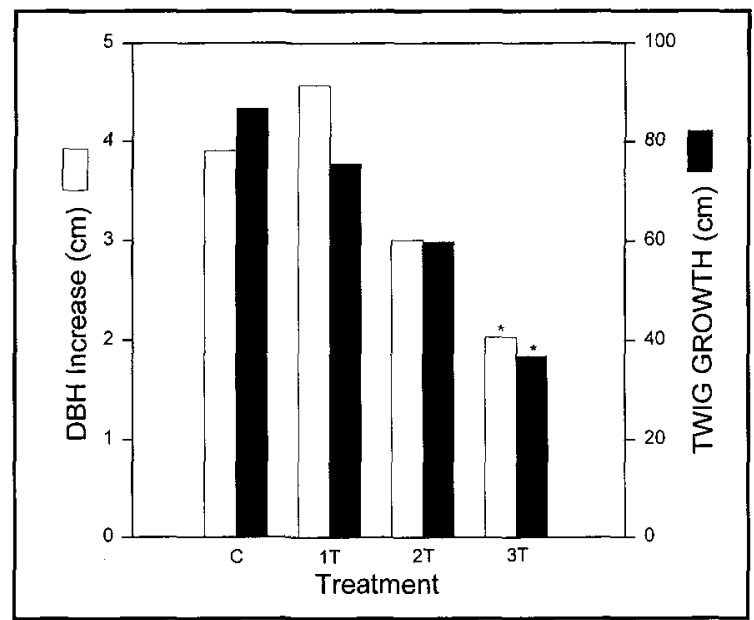

Figure 3. Total twig growth and dbh increase of pin oaks over 6 years after root loss from trenching and no compensatory crown pruning. An asterisk $\left(^{*}\right)$ denotes a significant difference from control at $\boldsymbol{P} \leq \mathbf{0 . 0 5}$ using Dunnett's test. 
preted carefully. These large growth reductions of $33 \%$ to $40 \%$ were significantly different from the control at $P \leq 0.1$ and were similar to growth reductions in 1992 and 1995, which were significantly different from the control at the more commonly accepted $P \leq 0.05$. Variable rates of recovery of individual trees combined with variability in measurements may both contribute to high variability.

These results are in agreement with a previous study (Miller et al. 1993) that showed a single trench can be tolerated by vigorous, relatively young trees. Trenches on more than 1 side may be much more stressful.

Twig growth. Annual twig growth data showed the same general pattern of growth reduction after root injury followed by recovery of growth rate in succeeding years but with greater variability (data not shown). Total twig growth over the entire 6-year period was related to trenching but significant only in the most severe (3T) treatment (Figure 3).

Dieback. Of all the trenching-only treatments, significant dieback was noted only in the $3 T$ treatment (Figure 4). The dieback rating was significantly greater than the controls starting the second year. Dieback of the $2 T$ treatment was higher (not significantly) than the controls in all years, with the largest differences in the first 2 years. Control dieback ratings rose in the last 4 years as lower branches died, a pattern that is typical of this species. In the $1 \mathrm{~T}$ and $2 \mathrm{~T}$ treatments, it appeared that the lower branches died sooner, but at the end of the experiment, dieback was similar to the controls. The more severe stress of the 3T treatment, especially in the separated groups, caused death of additional branches in portions of the crown, where deadwood development is not normal for pin oaks.

Effectiveness of compensatory crown pruning. Crown pruning was of greatest benefit when compensating for severe root loss. It affected twig growth measurements more than $\mathrm{dbh}$ increase.

Diameter growth. Compensatory crown pruning had no effect on total diameter growth for all 6 years compared to unpruned trees with the same trenching treatment (Table 1). From year

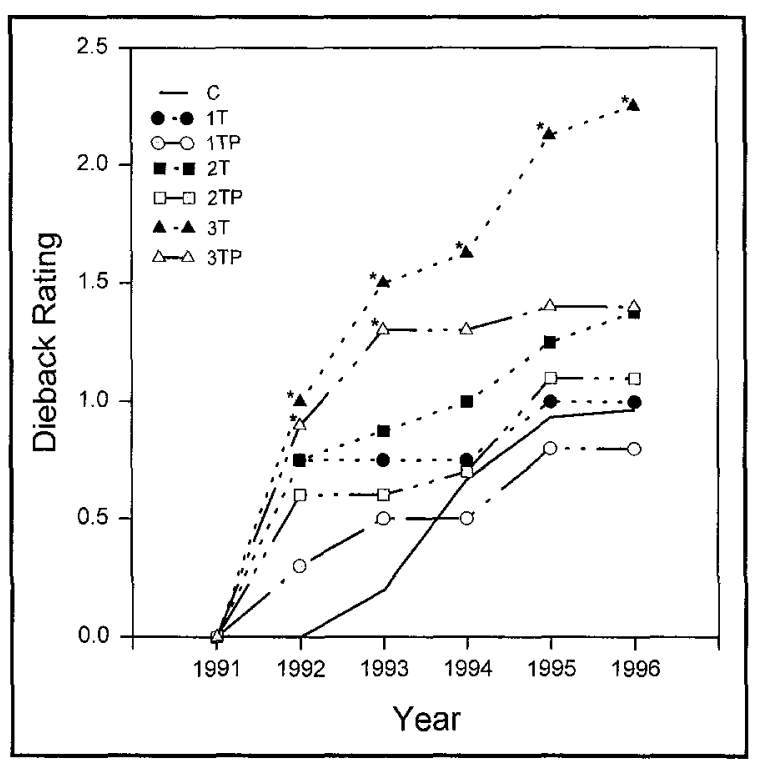

Figure 4. Dieback ratings of pin oaks. No dieback $=0$. Minor dieback of small lateral branches $=1$. Moderate dieback $=2$. Extensive dieback affecting amenity value $=3$ using Dunnett's test. An asterisk $\left({ }^{*}\right)$ denotes a significant difference from control at $P \leq 0.05$. Treatment key: $1 \mathrm{~T}, 2 \mathrm{~T}$, or $3 \mathrm{~T}$ indicates number of trenches; $P$ indicates crown pruning also.

to year, annual diameter increase was generally similar for pruned and unpruned treatments for each level of trenching (Figure 2). Pruning may have reduced diameter growth somewhat in the first year for each trenching treatment. The data are consistent, though not significant.

Twig growth. Each year, twig growth of the pruned trees was slightly better than on the unpruned trees with the same level of trenching, without exception. This resulted in increased twig growth (significant at $P \leq 0.1$ ) over the 6 years of the study for pruned trees compared to unpruned trees with similar root damage (Figure 5).

Total twig growth of 1TP treatment was greater than on the controls, which were not pruned. One possible explanation for this unusual situation could be that the pruning redirected the resources available for growth to fewer growing points (i.e., buds), resulting in increased growth of each remaining terminal but without an increase in overall growth of the tree. This is supported by a lack of increase in dbh after pruning 
Table 1. Treatment designations, descriptions, estimated root loss, and total diameter increase over 6 years. There was no significant difference in diameter increase between pruned and unpruned treatments with the same number of trenches.

\begin{tabular}{lccc} 
Treatment & $\begin{array}{c}\text { Sides } \\
\text { trenched }\end{array}$ & $\begin{array}{c}\text { Crown } \\
\text { reduction }\end{array}$ & $\begin{array}{c}\text { Dbh } \\
\text { increase }(\mathrm{cm})\end{array}$ \\
\hline 1T & 1 & No & 4.6 \\
1TP & 1 & Yes & 4.2 \\
2T & 2 & No & 3.0 \\
2TP & 2 & Yes & 2.8 \\
3T & 3 & No & $2.0^{*}$ \\
3TP & 3 & Yes & $2.0^{*}$ \\
C & 0 & No & 3.9 \\
\hline
\end{tabular}

*denotes significant difference from control at $P \leq 0.05$.

and may be the reason for the increase in twig growth for all three trenching treatments. An increase in total crown growth before regeneration of the root system could prolong the imbalance between the crown and root system. The limited number of trees available prohibited including a treatment of compensatory crown pruning without trenches.

Dieback. Dieback ratings were consistently, but not always significantly, lower for pruned trees than for trees with similar root loss that were not pruned (Figure 4). Dieback of 3T and 3TP treatments developed most rapidly. Both treatments had significantly greater dieback than the controls in 1992 and 1993. Starting the 4th year, only the $3 T$ treatment was significantly greater than the control. Compensatory pruning seems to be most beneficial in reducing dieback after severe root loss.

Application of study results. This study shows that the loss of roots causes growth reduction, dieback, and presumably stress, although stress was not measured directly. More severe root loss resulted in more severe and longer lasting growth reduction and dieback. No supplemental irrigation was provided, similar to the common situation on a construction site. A comprehensive irrigation program likely would have helped reduce the impact of the trenching.

For relatively young vigorous trees, there are many similarities between trenching and transplanting. Digging a tree from the nursery can result in the loss of $82 \%$ to $96 \%$ of the tree roots

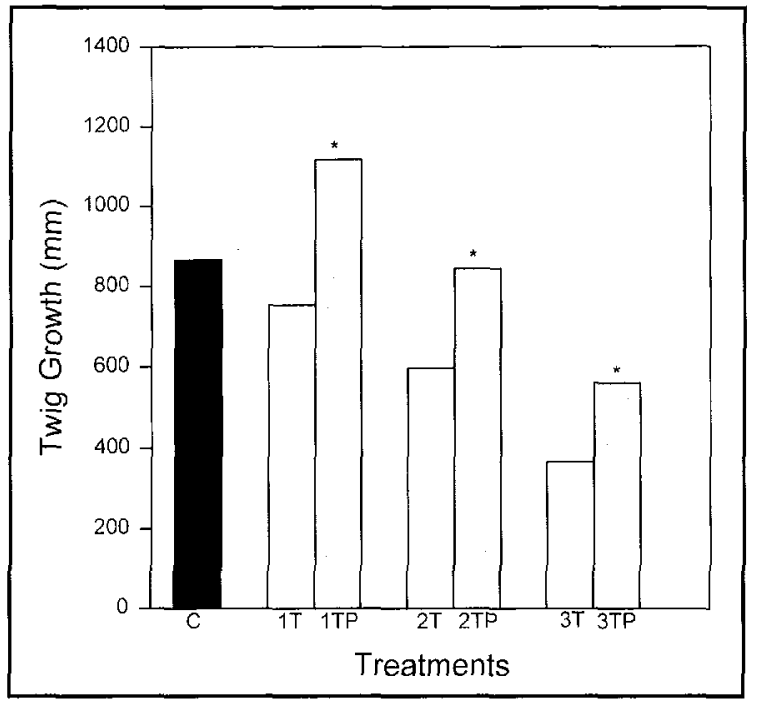

Figure 5. Total twig growth of pin oaks after root injury from trenching with and without compensatory crown pruning. An asterisk (*) denotes significant difference between pruned and unpruned trees at $P \leq 0.1$ using Student-Neuman-Keuls test. Treatment key: 1T, $2 \mathrm{~T}$, or $3 \mathrm{~T}$ indicates number of trenches; $P$ indicates crown pruning also.

(Watson and Sydnor 1987; Gilman and Beeson 1996 ). Despite this high root loss, vigorous nursery trees planted on a quality site and cared for (watered) until established have an excellent chance of survival. Similarly, if the site is repaired after trenching and adequate care is provided to speed root regeneration and minimize stress, vigorous younger trees have a good chance of recovery from moderate root loss. Growth of these trenched trees decreased initially like transplanted trees (Watson et al. 1986) and then recovered. None of these relatively young and vigorous trees were killed by trenching on three sides and the loss of the majority of the root system. Excavation of sample trench areas showed that roots were regenerating across the trench and into the undisturbed soil. If grade changes, surface pavements, or soil compaction prohibit root regeneration and prohibit the recovery of trees after trenching, they may not survive, just as transplanted trees may not establish well and be long-lived on poor quality or restricted sites.

Pruning out live branches has been discouraged on the basis that energy reserves are also 
removed (Shigo 1993). The data from this study do not support this statement. When comparing pruned and unpruned groups of trees with the same trenching treatment, there was no reduction in stored starch of pruned trees in any of the first 3 years (data not shown). Diameter growth was mostly unaffected, terminal twig growth was increased, and there was consistently less dieback with all pruning treatments. Pruning was most beneficial after severe root loss, as indicated by significant decrease in deadwood development for 3TP compared to 3T treatment during the last 3 years of the study. Because there was no evidence of growth or carbohydrate reduction, this study should alleviate fears of detrimental effects of moderate pruning to compensate for root damage. This study does not rule out the possibility that very severe pruning could affect carbohydrate reserves.

Deadwood development at all trenching levels was generally, but not significantly, less in pruned trees, when compared to unpruned trees with the same trenching treatment. Treatment 1TP had consistently, but not significantly, less dieback than did the control group in the last 3 years of the study. This suggests an interesting possibility that may be worth further investigation. Proper pruning may be able to remove branches that would otherwise soon die-and perhaps reduce water stress at the same timeas a result of reducing the leaf area. There is evidence that trees are designed to sacrifice certain minor branches during drought in order to improve the water balance of the remaining parts (Tyree and Sperry 1988). Learning to identify and prune out these branches out early may improve water status and general health in the rest of the plant.

Limitations of study results. Based upon these results, young, vigorous trees may tolerate a moderate amount of root loss associated with trenching. However, these results cannot be applied to all trees in all settings, and the results of this experiment should not be used to justify unnecessary trenching around trees. Three factors contributed to the resilience of these trees: 1) they were relatively young and vigorous, 2) they were growing in high quality soil without root restrictions on any side, and 3 ) pin oaks are rela- tively tolerant of disturbance compared to many other species. Older trees and stressed trees would likely be more severely impacted by disturbance. Trees growing in limited root space, such as street trees in a narrow parkway, probably would be more impacted by the partial loss of an already limited or asymmetrical root system. When a single trench was dug near older trees growing in the parkway between the sidewalk and curb, losses were $25 \%$ to $44 \%$, with an additional $10 \%$ of the trees exhibiting substantial dieback (Morel 1984).

The minimal impact of severe trenching and root loss in the $3 T$ treatment might be misleading. Several of these trees were in the middle of a group of 3 trees and had small crowns that were protected by the other 2 trees. The impact of severe root loss was probably reduced compared to more solitary trees. By the end of the study, these trees were in better condition than the other trees with 3 trenches that were growing in a less protected situation as part of separated groups of trees. If all the trees with 3 trenches were open-grown, with full crowns exposed to sun and wind (like many street trees), they may have shown much more impact from the root loss. When all of the roots on 1 or more sides of the tree are cut, there is naturally some concern over the stability of the tree. None of the trees in this study toppled over, or even began to lean. Trees within the stand tended to protect each other from severe winds. They were also in an area with limited access, reducing the potential targets if they did fall. Hazard trees created by trenching would be a greater concern in developed landscapes.

A few minor dead branches (dieback rating $<1$ ) were evident as early as the 2 nd year in several treatments, but it was not until the 4th year after treatment that dieback was serious enough to alter the form of the tree (only in $3 \mathrm{~T}$ ). Final judgement on impact of root loss may have to be delayed until at least 5 years has passed.

If root system injury can be avoided, it should be avoided. Trees are valuable, and no unnecessary risks should be taken. The cost of maintenance to improve chances of survival after root injury are likely to be considerable and may balance the increased costs of protective procedures 
such as augering. For situations in which root system injury cannot be avoided, all site factors should be taken into consideration by a qualified arborist in order to asses the potential for root system damage and the chances of survival.

\section{Literature Cited}

Fazio, J.R. 1992. Trenching \& Tunneling Near Trees: A Field Pocket Guide for Qualified Utility Workers. National Arbor Day Foundation, Nebraska City, NE. $32 \mathrm{pp}$.

Gilman, E.F., and R.C. Beeson. 1996. Production method affects tree establishment in the landscape.

J. Environ. Hort. 14:81-87.

Miller, F.D., and D. Neely. 1993. The effect of trenching on growth and plant health of selected species of shade trees. J. Arboric. 19:226-229.

Miller, N.L., D.M. Rathke, and G.R. Johnson. 1993. Protecting trees from construction damage. Publication NR-FO-6135-S. Minnesota Extension Service, St. Paul, Minnesota.

Morel, J.D. 1984. Parkway tree auguring specifications. J. Arboric. 10:129-132.

Olson, J., and P.H. Wray. 1979. Preventing construction damage to trees. lowa State University Extension Publication PM-909.

Schoeneweiss, D.F. 1982. Prevention and treatment of construction damage to shade trees. J. Arboric. $8: 169-175$.

Shigo, A.L. 1993. 100 Tree Myths. Shigo and Trees, Associates. Durham, NH. 80 pp.
Tyree, M.T., and J.S. Sperry. 1988. Do woody plants operate near the point of catastrophic xylem dysfunction caused by dynamic water stress? Plant Physiol. 88:574-580.

Wargo, P.M. 1975. Estimating starch content in roots of deciduous trees-A visual technique.USDA For. Ser. Res. Pap. NE-313.

Watson, G.W., E.B. Himelick, and E.T. Smiley. 1986. Twig growth of eight species of shade trees following transplanting. J. Arboric. 12:241-245.

Watson, G.W., and T.D. Sydnor. 1987. The effect of root pruning on the root system of nursery trees. J. Arboric. 13:126-130.

Ziza, R.P., H.G. Halverson, and B.B. Stout. 1980. Establishment and early growth of conifers on compacted soils in urban areas. USDA For. Ser. Res. Pap. NE-451.

Acknowledgements. This long-term study was made possible by annual grants from Hendricksen, the Care of Trees, Wheeling, Illinois, and by the assistance of many colleagues, research assistants, student interns, and grounds department staff at The Morton Arboretum in setting up the field plots, taking data in the field, and processing samples in the laboratory.

The Morton Arboretum

4100 Illinois Route 53

Lisle, IL 60532 